\title{
Publisher Correction: The smell of death and deCYStiny: polyamines play the hero
}

Joseph A. Combs (iD and Gina M. DeNicola (D)

Correction to: Nature Metabolism https://doi.org/10.1038/s42255-020-0260-3, published online 3 August 2020.

In the version of this article initially published, in Fig. 1, 'Spermidine $\rightarrow$ Spermidine' should have read 'Spermidine $\rightarrow$ Spermine.' The error has been corrected in the HTML and PDF versions of the article.

Published online: 24 September 2020

https://doi.org/10.1038/s42255-020-00303-5

๑) Springer Nature Limited 2020 